\title{
"Honestly, I Think it's Going Great so Far... I Did Have a Mental Breakdown" Examining the Experiences of Paid Residents in their First Year
}

\author{
Regina Rahimi (Corresponding author) \\ College of Education, Georgia Southern University \\ 11935 Abercorn St. , Savannah, Georgia, 31419, USA \\ rrahimi@georgiasouthern.edu \\ Nedra Cossa \\ College of Education, Georgia Southern University \\ 11935 Abercorn St., Savannah, Georgia, 31419, USA \\ ncossa@georgiasouthern.edu
}

\begin{abstract}
This paper examines results from interviews of four undergraduate teacher candidates who participated in the inaugural year of a newly designed paid residency program. A large regional university, in collaboration with its largest partner school district, developed this particular teacher residency model as a potential way to offer diverse clinical experiences for undergraduate students and help combat teacher shortages in high-needs schools. This study explores the experiences of the four undergraduate students who were selected and hired as paid teacherresidents during the pilot year of this program. Each participant had their own classroom in which they served as teacher of record with the same requirements, roles, and responsibilities as the other teachers in the building. Utilizing a constructivist framework, we share results from one-on-one interviews as well as focus group discussions about their experience during pre-planning, school opening, and the first months of this new paid residency. Emerging themes identified candidates' perceptions of starting the program and perceived issues, candidates' preparedness for the responsibility of teacher-resident, the role of the mentor teacher in their experience, and candidates' overall perceptions of the residency experience related to their sense of confidence and preparation for the profession. This research seeks to add to the field of Education and clinical practice and paid residencies. This research contributes to an understanding of the effectiveness of teacher residencies in the preparation of teachers.
\end{abstract}

Keywords: Teacher Preparation, Internship, Preservice Teachers

DOI: $10.7176 / \mathrm{JEP} / 13-5-01$

Publication date: February $28^{\text {th }} 2022$

\section{Introduction}

Currently, there is much interest in the areas of creative, meaningful teacher-internships, residency-partnerships, and teacher recruitment/retention in the field of Education. (Coffman \& Patterson, 2014). Our work, aiming to contribute to all these areas, seeks to help contribute to the literature by examining a newly developed model for undergraduate teacher residency and examining it as a model of clinical practice through listening to the experiences of the teacher candidates involved. This study examines the experiences of four paid residents as they traverse the inaugural year of this newly designed paid teacher residency program. In this paper, we examine how these paid residents experienced pre-planning, school opening, and the first months of this new paid residency, seeking to discern the teacher candidates' views of their preparation and challenges as they started this experience. Utilizing a constructivist framework, we sought to learn about each individual's experiences as paid residents, serving the dual role of a classroom teacher and undergraduate student. While each individual's experiences were different and unique, there were similarities that emerged. Participants provided feedback about their perceptions and expectations when beginning the paid residency, obstacles and challenges they faced in their role as a paid resident, their feelings of preparedness for the responsibility of being a teacher, the role and impact of their mentor teacher, and candidates' overall perceptions of the residency experience related to their sense of confidence and preparation for the profession.

\section{Review of Literature}

Issues of teacher recruitment and retention have become increasingly more critical, both nationally and internationally. Enrollment in teacher education programs across the United States and throughout the world have decreased, and attrition rates in the field have increased (AACTE, 2019). Nationally, 25 percent of first-year teachers leave the profession (Darling-Hammond, 2009; Ingersoll, 2001). Owens (2015) found that 47 percent of all teachers in the state in which this study takes place leave within the first five years of practicing, citing a number 
of reasons for this fleeing from the field, including candidates' citing "realistic preparation". Owens makes it clear that those of us involved in teacher preparation must contribute to seeking creative approaches to address the preparation and retention of the teacher population. While schools in all settings are facing troubles with teacher retention, this issue is particularly troublesome for high-needs urban schools (Freedman \& Appleman, 2009). With this in mind, teacher preparation programs are taking close examination of practices that can help contribute to teacher recruitment and preparation practices that will lead to longevity in the field and will support the schools most in need. As teacher preparation has come under criticism in recent years, beginning with the No Child Left Behind legislation that shone the spotlight on issues with teacher education programs, one approach to addressing and improving the preparation of teachers has been to increase clinical practice opportunities for candidates (Allsop et. al, 2006; Jung, 2010). Spooner et al. (2008) noted that, “...candidates who receive increased amounts of field experience and mentor opportunities to help them understand the realities of teaching are better prepared to deal with the complex realities of today's schools, classrooms and students" (p.264). Certainly, simply increasing clinical practice hours appears to offer greater experiences for candidates, however, the nature of these experiences also needs to be considered with a focus on increased authentic engagement in the field (Honawar, 2008; Guha et al., 2017a).

The teacher residency model promises to provide such authentic engagement in the field. Teacher residency programs have garnered a great deal of recent attention as a model for clinical practice (Washburn-Moses, 2017). In that vein, one of the most heavily examined practices in teacher preparation being studied today is the year-long residency program (Henning, 2018; Henning et al., 2018). Teacher residency programs, fashioned after the medical model of residency training, offer a means of immersing teacher candidates in the schools while undergoing intensive mentoring and support, similar to the model for doctors-in-training (Thorpe, 2014). According to the National Education Association Center for Great Schools, teacher residency programs offer a number of benefits relating to the goal of producing teacher candidates that are "profession-ready" (Coffman \& Patterson, 2014).

While there is support now from both philanthropic organizations and the federal government for residency programs for teacher candidates (Solomon, 2009), there is a wide range of designs in which residency programs are structured and implemented (Washburn-Moses, 2017). The definition that Washburn-Moses offered in her study examining the consistency of teacher residency programs nationally, " a yearlong mentorship program in which the prospective teacher teaches alongside a master teacher combined with licensure and Master's coursework offered by a partnering institution" (p.34), appears to echo the current universal, general idea of the teacher residency models and is consistent with the notions of teacher residencies national organizations use such as National Education Association and the National Center for Teacher Residencies (Azar at al., 2020; Coffman \& Patterson, 2014).

Teacher residency programs typically involve candidates who are working toward licensure and course work at the graduate level. Some examples of these programs are the Boston Teacher Residency Program, Georgia Residency for Educating Amazing Teachers (GREAT), the Seattle Teacher Residency. While these all vary in their implementation, a common thread among them is that the candidates serving as the teacher residents have obtained a bachelor's degree. It is in this way that the model we are examining differs.

While there have been other studies examining variations of paid residencies for undergraduate students (Burns et al., 2008; Henning \& Duffy, 2017; Worsham et al., 2014), they have largely focused on summer or short term paid clinical experiences to encourage undergraduate students to participate beyond their enrolled semester and do not require the candidates to take on the role of teachers of record, such as the University of Delaware Residency Program, University of South Florida Urban Teacher Residency Program, and the Monmouth University Teacher Residency Program. While sharing some of the traits of the model we are examining, programs like these offered to undergraduate students differ in the role of the teacher candidate and mentors through the experience.

While there is only an emerging body of research on teacher residencies, there appears to be some evidence that this model offers benefits to teacher candidates' preparation and student learning (Guha et al., 2017b). Early research suggests immersion in year-long residencies better prepares teacher candidates as they enter the field, thus leading to their retention in k-12 settings (deJong et al., 2013; Kim \& Cho, 2012; Hascher \& Hagenauer, 2016). Colson et al. (2017) conducted a study comparing teaching- self-efficacy in pre-service teachers enrolled in a traditional, 16-week teaching placement versus a year-long teaching placement. In their study, students completed the 24 questions Teachers' Sense of Self-Efficacy Scale created by Tschannen-Moran and Woolfolk Hoy (2001). The results of the study indicated that those students enrolled in the year-long placement had a higher sense of self-efficacy and professional preparedness than those enrolled in traditional, one-semester placements. Further potential benefits to the larger teaching profession offered by teacher residencies involve (among others): recruitment of candidates of color, development of strong partnerships between schools and universities, and addressing shortages within high-needs schools (Azar et al., 2020; Coffman \& Patterson, 2014).

Recognizing this model for its potential impact on teacher preparation and the p12 student learning, it is critical these models are examined and refined. It is our desire to forward the understanding of innovative clinical 
practice in teacher education through thorough examination of this particular paid residency model with its unique features of serving undergraduate students and placing them in their first professional roles while completing their degree programs.

Finding creative ways to sustain year- long residencies with teacher candidates can be a challenge (Friend, 2007; Guha et al., 2017a). To help address these concerns, one teacher preparation program, located in the southeastern part of the U.S. and our subject of this study, has searched for innovative and creative ways to help address decreasing enrollment and rising attrition rates within the local p12 teaching field. This served as the impetus for the involvement in the creation of the teacher residency program.

\subsection{The Paid Residency Model}

The model was conceived through collaboration in which one university sought to help the local school district explore ways to address their teacher shortage. The residency program also appealed to the university for its potential in preparing its teacher candidates. Members of the college of education began to consider the model after attending a professional conference session on teacher residency programs. A collaborative team was formed with members of the college of education administration and members of the local school district. Over the course of two years, they developed a model that allowed selected teacher candidates from the university to work as classroom teachers in salaried positions within the district, under the guidance of a mentor-teacher. Beginning in fall of 2020, they piloted this paid residency program. The inaugural year involved four teacher candidates assuming positions (hired as teachers of record) in the school district. Since these teacher candidates were still working to complete their undergraduate degree in teacher education, each participant had remaining coursework to complete during this year, varying from 12 to 18 credit hours. Candidates interested in the paid residency (vs. the traditional semester-long student teaching experience) were required to apply and went through a rigorous interview process with both the university and the district. All four teacher candidates who applied were accepted into the program and hired on a one-year contract by the school district. They were placed in one of two Title 1 urban schools (one elementary and one middle school), selected by the school district. It should be noted that many teacher residencies programs are focused on urban schools or "hard to staff" districts (Marshall \& Scott, 2015) such as in this case.

For this model, the district hired two mentor teachers, one for each school. Prior to becoming mentor teachers, both were serving as classroom teachers within the school district. They were required to apply for the position within the school system. Students applied for the paid residency during the spring of their junior year. In order to be eligible, students had to be enrolled in either the university's elementary or secondary education undergraduate initial licensure programs, be in good academic standing, and entering their senior year in the subsequent fall semester. While the final decisions were made by the school district, members of the university's college of education were also involved in the interview process for the mentor teachers. Under this model, while two teacher candidates fill positions within one school, the designated mentor-teacher for the site comes out of her/his position as classroom teacher, thus one of the teacher candidates assumes the role of teacher of record for that classroom. The second teacher candidate assumes the role of classroom teacher in a vacant classroom within the school. The mentor teacher (hired as such by the school district) is responsible for mentoring both teacher residents at that school site. The teacher residents are compensated through a formula designated by the school district in which a beginning teacher salary is "split" between the two teacher residents during this residency year, even though they are assigned as the teacher of record for the entire school year. The mentor teacher is compensated by the district by receiving her/his teaching salary for the work as the mentor teacher. Also, as part of this model, the teacher candidates are required to attend the district-wide orientation sessions offered by the school district prior to them officially beginning the school year. The university supports the candidates very similarly to the support traditional student teachers enrolled in the semester-long experience receive. Each candidate is assigned a university supervisor who is responsible for observing candidates' teaching and classroom performance and providing feedback on the instruments utilized by the teacher preparation program for monitoring candidate proficiency.

As undergraduate students, while these teacher candidates were serving as a teacher of record, participants were still required to complete all coursework necessary to graduate in the spring. This posed some obstacles because many of their classes were during times which they were teaching. Faculty had to adapt course syllabi specifically for them in order for the paid residents to complete their courses. Most notable was the time of the course and format of delivery. University faculty supported them by revising course assignments, providing asynchronous instruction, and meeting with them individually to provide support throughout the course.

Our study seeks to examine the inaugural year of this model for its contribution to teacher preparation, particularly examining the teacher candidates' experiences and perceptions of preparation throughout the first few months of this residency. 


\section{Design and Methodology}

\subsection{Theoretical Framework and Data Collection Methods}

This initial study examines this pilot paid residency model which follows paid teacher residents (current undergraduate teacher candidates) as they begin the school year in this program (starting with pre-planning and school opening) assuming the responsibilities of a classroom teacher with support from the school and the university. While this is a small-scale study it has the potential to develop further as the paid residency model expands within the district and beyond, having larger implications for the field. It is part of a larger study seeking to examine the impact of the collaborative paid residency program on enhancing candidates' sense of professional development and preparedness, their perceptions and understanding of contemporary classroom settings, as well as their retention in the field. This particular study examines the residents' experience with school opening and the subsequent first months of school.

\subsection{Theoretical Framework and Data Collection Methods}

We approached this study from a constructivist paradigm as we sought to learn about teacher candidates' perceptions, understandings, and the impact of such an experience on their sense of professional development. We recognize that each participant will have different experiences because of unique and individual background and socially constructed norms which they brought prior to beginning the paid residency. With this in mind, we are not looking for "right or wrong" answers but instead are exploring each individual's experience in this pilot program to understand their perceptions of this teacher residency model. Data was collected in the form of oneon-one semi structured interviews and focus group discussions. All interviews (Appendix A) and focus group discussions (Appendix B) were conducted through Zoom during the months characterizing pre-planning, school opening and the first three months of the teacher residents' teaching experience.

The semi-structured interviews and focus group sessions were audio recorded, transcribed, and analyzed for emerging themes related to issues of early experiences of the candidates, the candidates' preparedness for the responsibility of teacher-resident, and candidates' overall perceptions of the residency experience. Our guiding research questions sought to examine the experiences (challenges and opportunities wherein) of teacher residents as they begin as classroom teachers in this paid residency model.

\subsection{Participants}

The participants in this study were undergraduate students enrolled in their senior year of either the Secondary or Elementary Education programs at a large public university in the southeastern United States. They applied to be part of the paid internship experience through a process developed by the university's College of Education, choosing to participate in this teacher residency experience rather than the traditional semester-long student teaching semester in which teacher candidates observe and teach within a certified teacher's classroom. The application and respective selection process were created by members of the COE (not the researchers) as well as the school partnering district in which the candidates would be placed. The researchers had no role in the selection of these candidates as paid teacher residents.

All four students accepted into the yearlong paid residency agreed to participate in the study. Pseudonyms were used to ensure anonymity. Because we approached this study through a constructivist lens, it is important to recognize the unique characteristics of the individual participants in this study. Importantly to note, while we did not seek to examine this model for its potential to recruit diverse teacher candidates, three of the four candidates enrolled in this program were students of color. This aligns with other research suggesting teacher residency programs can be important vehicles for the recruitment of black teachers (Azar et al., 2020). This will be important to continue to examine in future iterations of this program.

Jayden is a 25-year-old black male majoring in Middle Grades Education in ELA/History. He was hired to teach history in middle school. The mentor-teacher assigned to him is a 25 -year veteran ELA teacher. Jayden is also taking four classes during his first semester on the job as a teacher resident. His reason for applying to the paid residency related to his age and work experience, "I am ready to teach. I have been working for a while. The best experience to be prepared to teach is to just do it".

Amelia is a 23-year-old white female majoring in Secondary Education, Mathematics. She is teaching at the same middle school as Jayden and they are sharing the mentor-teacher. Amelia was hired to teach middle grades math. She began the paid residency also taking an additional 12 credit hours at the university. She noted her reason for signing up for the experience was she, "... thought it would be the best way to be prepared".

Deja is a 22-year-old black female majoring in Elementary Education. At the start of the paid residency, she was working at another job part-time and also taking two classes from the university. Her mentor-teacher is a 12year veteran Elementary Education teacher. Deja, citing her work history, offered this as her reason for choosing this experience,

I'm not gonna lie. Number one, it was paid. I might as well just teach and get paid. I mean I would have a mentor teacher, and I would have the support of the university and a little bit more support from the 
school because I am a teacher- resident instead of an actual teacher.

Brianna is a 22-year-old black female majoring in Elementary Education. She also is working with the mentor-teacher that Deja works with as they are placed at the same school. Brianna also started the semester working another job while taking 18 hours of coursework. Her reasons for joining the paid residency program seemed to focus on the notion of practicality, "I was like it's a great opportunity if it is going to be similar to what I was already gonna be doing (field placements)".

\section{Findings}

Several themes emerged from the study that serve to provide insight into the experiences of teacher residents in this residency model, challenges they faced, and their reflections of their preparation and professional experiences in navigating their first few months of teaching through this model. Emerging themes related to: the role of communication in framing the model and beginning the experience for these residents; the sense of preparedness presented by teacher residents, issues related to knowledge and preparation as they began their first year teaching while still in their undergraduate program, the role of mentoring in their first months, implications of transitioning from online to hybrid models of teaching during their first year (teaching during the pandemic) and their overall perceptions of the experience and the model. Our purpose in presenting these findings, (including the challenges and "missteps" in the roll out of the model) is simply to highlight the experiences of paid residents in this model to support future development of successful paid residencies.

As we began the interviews with the teacher candidates in mid-summer shortly after they had received word that they had been accepted into the residency program from the university and hired by the school district, it became clear that in this inaugural year of this paid residency program (and in the midst of the global pandemic of 2020), that this would indeed be a challenging time and one that needed to be documented through examining paid residents' experiences as a means of helping to examine this model for clinical practice and teacher preparation.

\subsection{Communication}

One of the first themes to emerge involved the communication with the university, the district, and the school regarding the paid residency. Teacher candidates perceived that communication was limited and vague, noting how this caused additional stress to the start of the experience. They specifically referenced a lack of communication regarding their acceptance into the paid residency, the school site where they would be teaching, the content areas and grade levels they would be teaching, their role in the classroom and how the university would adjust their course schedule when it conflicted with school hours. While many of this can be attributed to the firstyear roll out of the program, it did cause some anxiety for the candidates. At this point, there had not been an established protocol collaboratively developed by the partners for candidates transitioning into the residency.

The teacher candidates struggled with getting the information needed to adequately prepare for the upcoming school year as teachers of record within their own classrooms. They specifically referenced a lack of information or misinformation about grade level and content area(s) they would be teaching and even indicated that they frequently had to be the ones to initiate contact with their questions. Jayden shared his frustration about the lack of communication as he explained, "Once I got hired and went through the whole process, I did email folks. It probably took two weeks for me to hear something... I would have to email people multiple times for them to give me some information." He further elaborated on communication concerns when he explained that while he initially was told he would be teaching two subject areas to later find out his teaching assignment was changed to just one subject. This information was provided to him only weeks before the start of the school year and served to be a source of frustration for him as he sought to be prepared for his new role.

Deja was hired for a position in the other school but shared similar experiences to Jayden. She expressed that she felt like she was "left out of the loop a lot of times" and reported that she had to be the one to initiate contact with the school site to find out important information.

I have spoken with her (a member of the school personnel) maybe once or twice. I wanted to inquire about what grade I was gonna teach because we needed to know that for the [district orientation program]. I emailed her and asked what grade I was going to teach...to know what the plan is for that would be helpful.

She did not find out what grade she was teaching until three days before the district's orientation.

Amelia did not initiate contact as Jayden and Deja did. Instead, she waited to hear from the school. She was unsure about even her status as a hired paid intern until very close to the start of the semester. She shared with us how the last-minute notification overwhelmed her.

I was just told where I was gonna go. Then it was all the sudden, very sudden. I finally was told where I was gonna be and what I was gonna be teaching. Then it was like, 'Oh, now next week you're doing your orientation.

Participants did not receive information regarding either the district, school, or university's expectations of them. There was not an initial orientation providing any rules, procedures, or guidelines as they began the school 
year. Participants provided some suggestions about how future students might be better supported. During one of the group discussions, Deja suggested having information readily available would prove helpful when she stated, "I think it would honestly be nice if they came up with a paid internship FAQ maybe on the district website... that we could have because there was [sic] just a lot of questions we had." Brianna agreed with Deja when she followed up "instead we had all these simple questions, but nobody really knew the answers." Another suggestion the participants had involved having someone who they could direct all their questions to. Brianna suggested that it would be beneficial to have a point person, "someone we contact personally that said, 'Hey, if you have any questions '... then kind of met [sic] up. ” Both Deja and Brianna agreed that perhaps would have lessened the stress and anxiety these candidates experienced prior to the start of this school year.

The interviews with the candidates are indicative of the needs for clear communication prior to the academic year beginning and early communication that is critical for new teacher residents to begin their school year with ease and confidence. The teacher residents relayed that they were not certain of the details of this model and the role of the mentor teacher prior to the start of the school year. Additional resources, such as written guidelines as well as a point of contact for questions prior to the year beginning would have proven helpful.

Sense of Preparedness

Also emerging from our interviews with the teacher residents were both their notions of readiness and selfconfidence in taking on this role (prior to beginning) and their reflection on their professional preparation for the role of teachers once they began. In many ways, the teacher residents appeared overly confident as they first began to engage in the work of a classroom teacher. However, we noticed a shift as the semester progressed.

Early comments from the participants captured this sense of confidence. Jayden reflected on his work as a classroom teacher during the first week of school,

I have been doing this-full time class, full time working thing for the past two years, maybe even longer than that, so I'm used to it. I'll try to knock out my class work Sunday, Monday, Tuesday, and then the rest will be devoted to planning and grading. I'm good. I'm very organized and I know when it's time to work on different stuff, so I will be able to handle it.

Brianna also expressed a great deal of confidence in her ability to handle the responsibilities of a classroom teacher prior to beginning the semester,

I'm gonna say I'm about 70 percent confident only because I know teaching and because since my freshman year I've had a job, which was almost full time and I did school full time, so I feel pretty good about being able to juggle responsibilities and juggle my job, and teaching and everything else in the school.

The teacher residents seemed to suppose that since they have maintained a job throughout their educational experience, that the responsibilities of teaching would be similar to that level of work

However, just a month into the paid-residency experience, we began to see a shift in their reflections of the work of classroom teachers and the level of responsibility they as teacher residents now have. Their sense of selfefficacy clearly waned as they moved into their first few months.

Deja captured this shift in perception,

I will say that it has been very stressful. We're just in pre planning right now and I feel like it's way more than I thought it would be. When I completed the application to do it, I was thinking "oh it's only a little more work that what I would already be doing. I feel like it's definitely not 8:00 to 4:00. It's like I am constantly getting emails and I am constantly trying to think of what I have to do. It feels like it never stops. I think I didn't really understand how much agency I would have as a teacher.

Brianna also talked with us in great detail about the stress she was experiencing in the first few weeks of teaching

Oh, honestly, I think so far it's going great, the teaching part. I did have like a mental breakdown probably like last Friday. It was just real hard. I was like, I started crying. I'm just like, "What is going on?" I don't know how other teachers are getting through everything they're supposed to in a day. I'm like, there is not enough time in the day!

Jayden, while remaining confident of his teaching ability, reflected on the other duties he felt unprepared for, " Teaching' is teaching, but there's so much more to being a teacher: the planning, the district assessments, the workshops, all of that."

Further, the teacher residents reflected on specific topics they felt unprepared for as they entered the field. This information provided insight into our teacher preparation program. Since this was during the pandemic and the schools were fully online during the first few months of the school year, Jayden noted, "The toughest thing is once the school shut down, we had to do the Google online assessments and stuff. We weren't really taught how to teach online that much." He also noted again how some of the professional duties have not been emphasized pre-practice, "I think there is a lot of paperwork and legal stuff. I don't think that gets taught to us, so we know what to expect. I don't really know how you would teach that." He also found it,

It was shocking to realize the kids aren't at grade level, so some of the stuff that I expected them to do, 
they can't do at this moment. I'm going back and revising my plans to scale it back and try to scaffold them, to build up to where I want them to be.

Brianna, reflected on lessons she learned thus far,

I didn't know how important it was to put together a classroom supplies list. Very important, and it's very meticulous, and I used to think teachers just slapped stuff on there to just have my mom pay for extra stuff, and now I'm sitting here, and I'm like, I put out a regular generic classroom list, and now I'm like, "Oh, my gosh, I need this, and I need this and I need them to have this. It's even worse because we're virtual because some stuff that I would have had in the classroom and not needed for them to get; I don't have that to give them.

Deja also noted that she wished she had a bit more experience in preparing for this first year, "I wish I had a little more practice with RTI. Something that's really intimidating for me because I feel like I'm not prepared for it, but maybe I will be, and it might be a piece of cake".

Amelia commented on the real struggles of teachers purchasing their own items.

I was surprised by supplies and things. I wasn't really ready to purchase supplies for my classroom and stuff like that because I never expected to have to do that. I wasn't really ready to buy all this stuff at one time for a brand-new classroom. That was a big shock.

Many of the concerns articulated by the teacher residents related to their knowledge of professional duties. This has served to remind us to better prepare candidates for their vocational responsibilities prior to their induction experiences, such as the paid residency to prepare them to be "profession ready".

4.3 Role of Mentoring

Clearly, the most important factor in this particular model, as likely with other residency models, is the relationship between the teacher residents and the mentor-teacher (Sober, 2020). In our interviews with the teacher residents in this study, we found this relationship has been critical to their development thus far.

Deja repeatedly spoke about her mentor and how accessible and helpful she has been,

Whenever I had any question or issue, I immediately called my mentor teacher. She has been my lifeline through this. We have a lot of contact together. She helps me a lot with the administrative sides of things as well as the teaching things. She gives me resources, and she's always giving me reminders and teaching me how to do things because I do find. She's helped me out a lot."

Brianna also has talked about her mentor teacher and the important support she provides, for example, "She (the mentor teacher) is teaching math for us (both of the teacher candidates) right now this week just so we can get our heads wrapped around teaching math because I don't want to teach them (the students) wrong." The mentor teacher in this role appears to offer daily support to both teacher residents assigned to her. However, it should be noted that in two of the teacher resident-mentor pairings, the mentor-teacher's content area doesn't align with either of the teacher residents with whom they are working. The teacher candidates, while gaining insight from the mentor-teacher's vast years of experience as a classroom teacher, have noted that they also must seek guidance from academic coaches and content area teachers with their building as well as university support to help them with their content-specific instruction. This highlights the importance of how important the matching of the teacher residents to the mentor teacher is in the residency model.

One other potential concern that arose from the interviews with the candidates pertains to "sharing" mentorteachers. In this model, two candidates are assigned to one mentor teacher. In the case where one teacher resident may appear to require more "attention" from the mentor, one of the teacher residents may be somewhat slighted, causing the teacher residents to vie for time and resources. One of the teacher residents illustrated this, but at this point didn't appear to be impacted by it.

4.4 Experiencing the Residency in a Pandemic

While this was an unexpected aspect of this study when we first sought institutional approval, it nonetheless impacted how the inaugural year of the residency unfolded. As the teacher residents began this experience amid the COVID pandemic of 2020, they also were dealing with the unprecedented experience of schools being fully online. From this perspective, they were not "novices" since no teacher (no matter their level of experience) had any prior knowledge of how to deal with this. In this way, the teacher-residents felt as equipped as the other teachers and in some instances given their recent exposure to educational technology, they felt more prepared. Jayden noted,

I think the whole school is struggling with that because you need to be in person with the SPED students. My parapro, he's in there during the first, sixth, and third periods. I think he might be struggling a little bit. I try to help him, but we really don't know what to do. He calls the parents and tries to help them that way, but it's virtual learning. It's tough.

Deja reflected on her experience with virtual learning,

I had horrible technology issues, and that's another thing. Everybody always has technology issues. Between myself or my students, somebody's always having an issue. Today I was the one who had technology issues. My school- issued laptop just stopped working. It wouldn't turn on. It just starts 
beeping. My students were very flexible and worked with me, but it's tough for sure.

Brianna summarized her first few months of dealing in the virtual environment as, "my main struggle right now is trying to take everything from what we could do in the classroom and put it in virtual. It has been clear that the teacher residents, as teachers have done throughout this pandemic, have risen to the occasion and sought best strategies and practices for engaging their students.

\section{Conclusions and Implications}

Our research focused on learning about four students' experiences in a pilot program which placed them in the position of a classroom teacher during the final two semesters in their undergraduate, initial licensure program. The constructivist framework which guided our study, allowed us to capture the individual experiences of each participant. We recognize and acknowledge that their social and cultural experiences contributed to different and unique experiences to the paid residency. Our interviews with the paid residents shed light on their experiences over the first several months in the classroom and provide insight into the pilot program as a model for clinical practice. This study and the insights from the participants give us a first-hand account into their experiences as a paid resident employed by the school district juxtaposed with their role as a university student completing their final year before graduation. This study has provided important considerations for developing and refining teacher residency programs. Our research indicates that paid residents may benefit from earlier and clearer communication from all parties. Oftentimes, the paid residents had to seek out information themselves from their respective schools as well as the district but did not always know who to contact with those questions. In some instances, they even had to send multiple emails to get a response. Clearer communications from the university about certain requirements and expectations would have helped ease anxiety and concern about their courses. These issues could be eradicated with the development of a collaboratively designed "handbook" or mechanism for communicating expectations. Because all the participants were enrolled in required courses that overlapped with their classroom teaching, modifications needed to be made to ensure that students would be able to continue teaching and be successful in their courses. Those modifications were not created or shared with them until after the school year began. If this information is provided as early as possible, we anticipate future candidates experiencing less anxiety prior to the start of the school year.

The paid residents in this study provided valuable insight into areas of professional development and knowledge that needs to be expanded in teacher preparation programs. Their interviews remind us that we need to work closer with partners to ensure teacher candidates have adequate knowledge of current policies and practices and are adequately prepared to assume those professional responsibilities immediately upon entering the field.

Participants highlighted that their mentor teachers played a critical role at their designated schools. The mentor teachers supported them in areas of both content and pedagogical development. Because the mentors had previous experience as classroom teachers in the school district, they were also able to provide insights that university supervisors could not. The participants actively sought out their mentors with questions, concerns, and feedback about their instructional practices. Based on the feedback from the participants, the mentor teacher should continue to be utilized to support paid residents. Participants' statements regarding the importance of their mentor supports existing research on the role that mentors play in supporting new teachers, especially in low socioeconomic status, high needs, at risk schools where teacher attrition is often highest (Broad \& Muhling, 2017; Freedman \& Appleman, 2009; Kardos \& Johnson, 2010; Kutsyuruba et al., 2017). However, it appears it would be optimal if the mentor teachers shared experience in teaching the same content area in which the teacher residents are hired to teach. Also, caution needs to be taken to assure that both teacher candidates and mentor teachers are provided ample time and resources and receive the similar benefits from the mentor-teacher relationship.

\subsection{Implications}

This study offers insight into the experiences of teacher candidates as they have traversed the first months of a paid residency. As this residency program immerses undergraduate candidates in the profession immediately, taking on the role of teacher of record, it is important to examine the early processes involving their beginning of this experience. As we look through the experiences of these candidates, they have told us a great deal about how the start of this program can be improved, providing implications for other programs engaging teacher candidates in residency models. The candidates reminded us that strong communication and expectations from all stakeholders are necessary, the selection and training of mentor teachers is imperative and the pairing of these individuals with the teacher candidates is critical. These statements align with existing research on the important role mentoring play in early career educators (Kardos \& Johnson, 2010; Kutsyurba et al., 2017). We have also gleaned from these candidates that our teacher preparation programs should connect with our local school districts to be sure we are preparing our candidates for the professional tasks (not just pedagogical and instructional) that is expected of them in the field. Lastly, we need to provide candidates with diverse experiences to help them be prepared for the work ahead of them.

As noted above, this model could offer potential for recruiting diverse candidates as other research has 
suggested (Azar et al., 2020). This will be important to continue to examine in future iterations of this program as we move forward and continue research involving this model. We plan to continue following these paid residents after they graduate and into their second year of teaching. We hope this project encourages others to examine residency programs as opportunities for clinical preparation of teachers. Currently, we do see the potential for this model to strengthen teacher preparation as others have found (Freedman \& Appleman 2009; Henning, 2018; Guha et al., 2017b, Yun \& Demoss, 2020). As one of our participants shared,

I think it's a good thing. A lot of the teachers here tell me that they did not have this type of support their first year. I would say we have more than the support that we need, which is good, so I would recommend it.

For future research, we hope to follow these teacher candidates as they traverse the next few years of their practice and monitor their retention in the field. We also hope to examine the experience of the mentor teachers as they serve to prepare the teacher candidates in these residencies. We hope to continue to examine this model of teacher preparation as a means of preparing effective teachers in the field.

\section{References}

Allsop, D. H., DeMarie, D., Alvarez-McHatton, P., Doone, E. (2006). Bridging the gap between theory and practice: Connecting courses with field experiences. Teacher Education Quarterly, Winter, 19-35.

American Association of Colleges for Teacher Education. (2019). Colleges of Education: A National Portrait. Washington, DC: author.

Azar, T., Hines, E., Scheib, C. (2020). Teacher residencies as a vehicle to recruit teachers of color. Report provided for the National Center for Teacher Residencies.

Broad, K. and Muhling, S. (2017), Voices of hope: sustaining learning through a protracted and jagged entry to the teaching profession in Ontario, in Kutsyuruba, B. and Walker, K.D. (Eds), The Bliss and Blisters of Early Career Teaching: A Pan-Canadian Perspective, Word and Deed Publishing, Burlington, pp. 139-153.

Burns, B. A., Grande, M., \& Marable, M. (2008). Factors influencing teacher candidates' participation in a paid field experience with urban students. Issues in Teacher Education, 17(2), 101-116.

Coffman, A., \& Patterson, R., (2014). Teacher residencies: Redefining preparation through partnerships. Report provided by the National Education Association.

Colson, T., Sparks, K., Berridge, G., Frimming, R., \& Willis, C. (2017). Pre-service teachers and self-efficacy: A study in contrast. Discourse and Communication for Sustainable Education, 8(2), 66-76. doi:http://dx.doi.org.libez.lib.georgiasouthern.edu/10.1515/dcse-2017-0016

Darling-Hammond, L. (2009, February). Teacher education and the American future. Charles W. Hunt Lecture. Presented at the annual meeting of the American Association of Colleges for Teacher Education, Chicago.

deJong, R., Mainhard, T., Tartwijk, J., Veldman, I., Verloop, N., \& Wubbels. T. (2013). How pre-service teachers' personality traits, self-efficacy, and discipline strategies contribute to the teacher-student relationship. Educational Psychology, 84, 294-310

Freedman, S. W., \& Appleman, D. (2009). In it for the long haul: How teacher education can contribute to teacher retention in high-poverty urban schools. Journal of Teacher Education, 60, 323-337.

Friend, M. (2007). Co-Teach! A handbook for creating and sustaining effective classroom partnerships in inclusive schools. Greensboro, NC: Marilyn Friend.

Guha, R., Hyler, M. E., \& Darling-Hammond, L. (2017a). The teacher residency: A practical path to recruitment and retention. The Education Digest, 83, 38-45. Retrieved from https://search.proquest.com/docview/1932126413?accountid $=11225$

Guha, R., Hyler, M.E., Darling-Hammond, L. (2017b). The power and potential of teacher residencies. Phi Delta Kappan, 98(8), 31-37.

Hascher, T., \& Hagenauer, G. (2016). Openness to theory and its importance for preservice teachers' self-efficacy, emotions, and classroom behavior in the teaching practicum. International Journal of Educational Research, 77, 15-25. Henning, J. E. (2018). A sustainable teacher residency: Designing paid internships for teacher education. School-University Partnerships, 11(3), 1-16. Retrieved from https://search-proquestcom.libez.lib.georgiasouthern.edu/docview/2322042051?accountid=11225

Henning, J. E., Bragen, Bernard F., Jr, Mulvaney, T., George,W. O. III., Duffy, G., Aldarelli, E., Borlan, C. A. (2018). The Monmouth university partnership: Redesigning practice. School-University Partnerships, 11(1), 3 Retrieved from https://search-proquestcom.libez.lib.georgiasouthern.edu/docview/2322041886? accountid=11225

Henning, J. E., \& Duffy, G. (2017). Design features for a yearlong clinical experience: Measuring student learning and using performance-based assessments. PDS Partners, 12(3), 3-5.

Honawar, V. (2008). Teacher "residencies" examined: Creating and sustaining urban teacher residencies: A new way to recruit, prepare, and retain effective teachers in high-needs districts. Education Week, 28(1), 5-10.

Ingersoll, R. M. (2001). Teacher turnover, teacher shortages, and the organization of schools (No. R-01-1). Seattle: 
University of Washington, Center for the Study of Teaching and Policy.

Jung, E. (2010). How field experiences prepare future teachers. Academic Exchange Quarterly, 14(2), 152-158.

Kardos, S. \& Johnson, S. (2008). New teachers' experiences of mentoring: The good, the bad, and the inequity. Journal of Educational Change. 11.23-44.10.1007/s10833-008-9096-4.

Kim, H., \& Cho, Y. (2012). Pre-service teachers' motivation, sense of teaching efficacy, and expectation of reality shock. Asia-Pacific Journal of Teacher Education, 42(1), 67-81.

Kutsyuruba, B., Walker, K.D., Matheson, I.A. and Bosica, J.G. Jr (2017), Mapping out the early career teachers' needs: findings from the pan-Canadian new teacher survey, in Kutsyuruba, B. and Walker, K.D. (Eds), The Bliss and Blisters of Early Career Teaching: A Pan-Canadian Perspective. Word and Deed Publishing, Burlington, pp. 21-46.

Marshall, D.T., Scott, M.R. (2015). Urban teacher residencies: Indicators of successful recruitment. New Waves, 18(2), 29-39.

Maxwell, J.A. (2013). Qualitative research design: An interactive approach ( ${ }^{\text {rd }}$ ed.). Thousand Oaks: Sage

Owens, S. J. (2015). Georgia's teacher dropout crisis: A look at why nearly half of Georgia public school teachers are leaving the profession. Retrieved April 15,2019, from https://www.gadoe.org/External-Affairs-andPolicy/communications/Documents/Teacher\%20Survey\%20Results.pdf

Sober, T. (2020) Identifying and recruiting quality mentor teachers. In C.Torrez and M.Krebbs (Eds.) The teacher residency model: Core Components for High Impact on Student Achievement. Lanham, MD. Lexington Books.

Solomon, J. (2009). The Boston teacher residency: district-based teacher education. Journal of Teacher Education, $60(5), 478-488$.

Spooner, M., Flowers, C., Lambert, R., \& Algozzine, B. (2008) Is more really better? Examining perceived benefits of an extended student teaching experience. The Clearing House, 81(6), 263-270. doi:10.3200/tchs.81.6

Tschannen-Moran, M., \& Woolfolk Hoy, A. (2001). Teacher efficacy: Capturing an elusive construct. Teaching and Teacher Education. 17 (7), 783-805.doi:https://doi.org/10.1016/S0742-051X(01)00036-1

Thorpe, R. (2014). Residency: Can it transform teaching the way it did medicine? Phi Delta Kappan, 96(1), 3640.

Yun, C. \& DeMoss, K. (2020). Sustainable strategies for funding teacher residencies: Lesson from California. Learning Policy Institute.

Washburn-Moses, L. (2017). A national descriptive survey of teacher residency programs. School-University Partnerships, 10(2), 33-41.

Worsham, H. M., Friedrichsen, P., Soucie, M., Barnett, E., \& Akiba, M. (2014). Recruiting science majors into secondary science teaching: Paid internships in informal science settings. Journal of Science Teacher Education, 25(1), 53-77. doi:http://dx.doi.org/10.1007/s10972-013-9360-1

Appendix A

One-on-One Semi-Structured Interview Questions

1. What experiences have been the most difficult for you since beginning the paid internship? Why?

2. What skills/knowledge have you gained since beginning the internship?

3. What have you learned about your students since working in your internship?

4. How have you handled some of the challenges that you have faced?

5. What resources have you found available to you at your internship site?

6. How have you been able to connect with your mentor? Other educators at the site?

7. What interaction have you had with: principals? Parents? Counselors? Other teachers? Other school staff (e.g., instructional specialists, assessment coordinators)

8. At this point in your residency, what gaps in knowledge or skills do you feel you have right now?

a. Please provide some examples that explain why you feel that these areas are gaps

9. What resources do you need to be successful in your internship?

10. How confident are you in:

a. Your knowledge of the content you are teaching?

b. ability to meet your students' needs?

c. Ability to juggle the requirements of internship along with the responsibilities you are facing in the classroom/internship setting?

d. Your ability to be successful in the classroom as a teacher while simultaneously balancing coursework?

11. How often do you meet with your university supervisor?

a. What supports has the university supervisor provided?

12. How often do you meet with your Mentor-teacher?

a. What supports has the mentor teacher provided? 
b. Do you feel that your needs are being met?

13. How connected are you with other students in the building?

\section{Appendix B}

Semi Structured Focus Group Interview Questions

1. What have been your most challenging experiences in your internship? How have you/are you addressing them? What resources are available to you for supporting you through this challenge? To what extent has the university prepared you for this challenge?

2. What are some accomplishments that you have experienced while in the internship? Was this something you learned through the university or through the internship itself?

3. How well have you gotten to know your students? Through what means have you learned about students' experiences and needs?

4. How would you describe your level of confidence in your current internship experience? What are your strengths and areas of concern for you at this point?

5. What would help you feel more confident/successful in your classroom and internship experience?

6. How appropriate are the internship assignments for the work you are currently doing in the field/classroom?

7. What else would you like to share about your internship experience thus far?

8. How is your relationship/communication with other professionals? Parents?

9. How have you been managing the professional tasks of the job? 